\title{
Factors Correlating Perceptions of HPV and Vaccine Uptake among High School Students
}

\author{
Parastou Sadat Khalessi Hosseini, Karen Munoz, Cynthia M. Lakon, and Brandon Brown \\ University of California, Irvine
}

\begin{abstract}
Background: Human papillomavirus (HPV) is arguably the most prevalent sexually transmitted infection, and has been linked to a variety of health complications including cervical cancer, anal cancer, and anogenital warts. The HPV vaccine can prevent these health complications, but few studies have investigated the specific factors that impact HPV vaccine uptake. Methods: Two hundred seventy-five male and female high school students were surveyed in an ethnically diverse school district in southern California regarding HPV vaccine uptake and perceptions. Results: Less than one third of students reported their physician had discussed HPV vaccine with them, and fewer still for males $(\mathrm{p}<0.01)$. Students who did discuss HPV vaccination with their physician were significantly more likely to get vaccinated $(\mathrm{p}<0.01)$. Conclusion: These findings suggest the merit of the physician taking on a more active role during office visits to promote knowledge of HPV and HPV vaccine to all youth in this age group.
\end{abstract}

(c) 2014 Californian Journal of Health Promotion. All rights reserved.

Keywords: Human papillomavirus (HPV), HPV vaccine uptake, adolescent, education

\section{Introduction}

According to the Centers for Disease Control and Prevention (CDC), human papillomavirus (HPV) is one of the most common sexually transmitted infections (STIs) in the United States (CDC, 2012; Lambert, 2001; Friedman \& Sheppard, 2007). The CDC estimates approximately 79 million Americans are currently infected with HPV, with an overall prevalence of 31.9\% in 2013 (CDC, 2012; Damin, Ziegelmann, \& Damin, 2013; Hairiri et al., 2011). With 14 million new infections each year, HPV-related cancers have become a growing concern. In addition to causing the vast majority of cervical cancers, HPV is linked to approximately one-third of penile cancers, twothirds of mouth and throat cancers, and over $90 \%$ of cases of anal cancer and genital warts (CDC, 2011; Beatty, O'Connel, Ashikaga, \& Cooper, 2003). Data collected by the National Institutes of Health (NIH) from 2003 to 2007 was used to estimate that the number of cervical cancer related deaths will be approximately 2.4 per 100,000 women per year within the United
States (U.S. Department of Health and Human Services, 2013).

\section{Adolescent Exposure}

The CDC Youth Risk Behavior Surveillance survey reported that in 2013, $19.6 \%$ of $9^{\text {th }}$ grade, $29.4 \%$ of $10^{\text {th }}$ grade, $40.2 \%$ of $11^{\text {th }}$ grade, and $49.3 \%$ of $12^{\text {th }}$ grade students were sexually active (CDC, 2014). The U.S. Department of Health and Human Services (2014) estimates that adolescents age 15-24 account for approximately $50 \%$ of new STI cases each year. Adolescents' high STI contraction and sexual activity rates place them at high risk for HPV later in life. As such, the Advisory Committee on Immunization Practices (ACIP) recommends that all adolescents should begin receiving the HPV vaccine around 11-12 years of age (Hirth, Tan, Wilkinson, \& Berenson, 2012). It is recommended for females ages 9 to 26 and males ages 11 to 26 to complete the three-shot series as soon as possible. The CDC also promotes early vaccination due to the vaccines' increased effectiveness prior to HPV exposure. 


\section{Vaccine}

The HPV vaccine is a safe and effective way to protect against HPV types 6,11, 16, and 18, and is effective in reducing HPV prevalence (Jin, Lipold, Sikon, \& Rome, 2013). Research conducted on the vaccine's effectiveness for females ages 14-19 has found that HPV prevalence has decreased from $11.5 \%$ in $2003-$ 2006 to 5.1\% in 2007-2010 (Markowitz et al., 2013). While effective, HPV vaccine initiation and completion rates are still relatively low. Currently, the HPV vaccine is not grouped with other childhood vaccines and must be requested. One study examined HPV vaccine initiation and completion rates for 271,976 young females between the ages of 13 to 18 in the United States , and found that completion rates decreased from 55\% to 21\% from 2006 to 2009 (Hirth, Tan, Wilkinson, \& Berenson, 2012). Additionally, research suggests that a lack of patient information and education can negatively impact HPV vaccine uptake and acceptance (Sparks \& Villagran, 2010). Thus, education regarding vaccination has become an increasingly important tool for the prevention of chronic HPV and cervical cancer (CDC, 2012; Beatty et al., 2003).

The prevalence of HPV is largely associated with its asymptomatic nature as well as a lack of HPV knowledge. Controversies have arisen due to the newness of the vaccine, the sexuallytransmitted nature of HPV, non-transmissibility of HPV through non-sexual contact, and the high price of the vaccine (Colgrove, Abiola, \& Mello, 2010). Foundational theories of health behavior suggest the salience of some key intrapersonal factors that could decrease the chances that an individual might engage in a preventative health behavior, including low levels of perceptions of the severity of an illness and ones' susceptibility to it, a lack of perceiving benefits to undertaking a preventative health action, and strongly perceiving barriers to undertaking a preventive health action (Rosenstock, 1974). Moreover, each of these factors might be precipitated by a lack of knowledge regarding the health consequences of failing to engage in a preventive action or of the benefits of engaging in the preventive health behavior. Additionally, the Theory of Planned
Behavior suggests that perceived normative beliefs regarding whether or not important referents such as friends and family approve of engaging in a health behavior, and as well one's motivation to comply with these norms relates to one's intention to engage in health relevant behavior (Ajzen, 1991).

If physicians actively adopt and promote HPV education campaigns, both the adolescents and their parents may feel more confident in the HPV vaccine. Gravitt (2011) noted that mothers wanted extensive information regarding the HPV vaccine, in addition to evidence linking HPV to cervical cancer, long before they would even consider vaccinating their children. Mergler and colleagues (2013) found that parents and their children's health care providers have similar views regarding vaccinations. As a result, healthcare providers may have a significant impact on a parent's openness to initiate a vaccine series. As such, we investigated factors that impact the initiation and completion rates of the HPV vaccine among high school students. The purpose of this project was to determine adolescents' knowledge and interest in the HPV vaccine, as well as the role of the physician in HPV vaccine uptake among adolescents.

\section{Methods}

\section{Sample}

This study included a convenience sample of students in one large ethnically diverse high school in southern California. The high school was selected based on its generalizability to Orange County's demographics. Students from eight classes $(n=275)$ were surveyed during one instructional period. In order to participate in the survey, students must have been between the ages of 13 and18. Both male and female students were surveyed. Participating classes were chosen based on grade level, class subject, and the teacher's level of comfort in having the survey administered in his or her class.

\section{Procedures}

The principal's approval was received from the participating high school prior to applying for and receiving IRB approval. The IRB waived 
the need for signed parent permission, as no identifiers were collected. Participating classrooms were confirmed prior to IRB approval via email. Before administration of the survey, participating classrooms were visited and and informational courtesy letter was sent home with each child. The lead researcher administered the survey according to a script for each class. Parents who did not want their child to participate were asked to e-mail the instructor of the course. Students who did not participate were asked to turn the survey over, whereas students who chose to participate gave verbal consent and proceeded to complete the survey. Upon completion of the survey, raffle tickets were handed out to participating students. A raffle drawing was performed in which one student from each class were given a gift card valued at $\$ 5.00$.

\section{Measures}

The outcomes of interest were whether the participant had received the vaccine, planned to receive the vaccine, and if they were interested in learning more about HPV and the HPV vaccine. The survey measures were based on a previous HPV study (Brown, Carcamo, Blas, Valderrama, \& Halsey, 2010). Survey questions pertaining to sexual activity were not asked because the sample population consisted of children. Demographic variables included gender, age, race, religion of the student, and religion of the parent.

\section{Analyses}

Descriptive statistics were conducted on the gender, ethnicity, religion of the student, religion of the parent, and age (see Table 1). Chi-square tests were conducted to determine if there were gender differences in receiving the vaccine and physician discussing the vaccine with a physician. Vaccine dosage received was stratified by gender, heard of HPV, age, and race; chi-square tests were run to determine whether vaccine dose varied by these background characteristics (Table 2). Binary logistic regression models were run to analyze the relationship between demographic characteristics and the following variables: heard of HPV, received the vaccine, plans to receive the vaccine, interest in learning, and physician discussed the vaccine (Table 3). Another set of binary logistic regression models were run to determine whether the physician discussing the vaccine, prior HPV knowledge, and plans on receiving the vaccine were associated with the likelihood of receiving the HPV vaccine series. Another binary logistic regression model was run to determine whether a physician discussing the vaccine, or a student's interest in the vaccine, would encourage students to plan on receiving the vaccine. A similar model was run used to evaluate the relationship of a physician discussing the vaccine with children's interest in learning more about HPV and the HPV vaccine. Finally, a linear regression was run to analyze whether students who had a physician discuss the HPV vaccine, had heard of HPV, or planned on receiving the vaccine, were more likely to

\section{Table 1}

Demographic Characteristics of the Sample $(n=275)$

\begin{tabular}{|c|c|c|}
\hline & $\mathrm{n}$ & $\%$ \\
\hline \multicolumn{3}{|l|}{ Gender } \\
\hline Male & 160 & 58.2 \\
\hline Female & 114 & 41.5 \\
\hline \multicolumn{3}{|l|}{ Race } \\
\hline Asian & 135 & 49.1 \\
\hline White & 93 & 33.8 \\
\hline American Indian or & 11 & 4.0 \\
\hline Alaska Native & & \\
\hline $\begin{array}{l}\text { Black and African } \\
\text { American }\end{array}$ & 7 & 2.5 \\
\hline $\begin{array}{l}\text { Native Hawaiian or } \\
\text { Pacific Islander }\end{array}$ & 5 & 1.8 \\
\hline Other & 21 & 7.6 \\
\hline \multicolumn{3}{|l|}{ Religion of Student } \\
\hline Catholic or Christian & 107 & 38.9 \\
\hline Atheist or Agnostic & 110 & 40.0 \\
\hline Muslim & 21 & 7.6 \\
\hline Buddhist & 6 & 2.2 \\
\hline Hindu & 5 & 1.8 \\
\hline More than one/other & 5 & 1.8 \\
\hline Jewish & 9 & 3.3 \\
\hline \multicolumn{3}{|l|}{ Religion of Parents } \\
\hline Catholic or Christian & 136 & 49.5 \\
\hline Atheist or Agnostic & 58 & 21.1 \\
\hline Muslim & 26 & 9.5 \\
\hline Buddhist & 15 & 5.5 \\
\hline Hindu & 10 & 3.6 \\
\hline More than one/other & 10 & 3.6 \\
\hline Jewish & 9 & 3.3 \\
\hline Mean Age (SD) & 16.13 & (1.175) \\
\hline
\end{tabular}


receive all three doses.

\section{Table 2}

HPV Vaccine Dose Received by Demographic Characteristics

\begin{tabular}{|c|c|c|c|c|c|}
\hline & $\begin{array}{r}\text { 1-2 HPV } \\
\text { vaccine } \\
\text { doses }\end{array}$ & $\begin{array}{r}3 \mathrm{HPV} \\
\text { vaccine } \\
\text { doses }\end{array}$ & $\begin{array}{r}\text { Did not } \\
\text { know/ } \\
\text { Other }\end{array}$ & $\begin{array}{r}\text { Total } \\
\text { responses }\end{array}$ & $\begin{array}{l}\chi^{2} \\
\text { (p) }\end{array}$ \\
\hline & n (\%) & n (\%) & n (\%) & n (\%) & \\
\hline All Participants & & & & & - \\
\hline $\mathrm{N},(\%)$ & 16 (11.7) & $26(19.0)$ & 95 (69.3) & $137(100.0)$ & \\
\hline Gender & & & & & $18.53(0.001)$ \\
\hline Male & 9 (12.9) & $4(5.7)$ & $57(81.4)$ & $70(51.1)$ & \\
\hline Female & 7 (10.4) & $22(32.8)$ & $38(56.7)$ & 67 (48.9) & \\
\hline Age (years) & & & & & $26.45(0.151)$ \\
\hline $13-16$ & $7(8.6)$ & 16 (19.8) & 58 (71.6) & 81 (59.1) & \\
\hline $17-18$ & $9(17.0)$ & 10 (18.9) & $34(64.2)$ & $53(38.7)$ & \\
\hline Race & & & & & $41.22(0.003)$ \\
\hline Asian & $5(7.8)$ & 7 (10.9) & $52(81.3)$ & $64(46.7)$ & \\
\hline White & 7 (14.3) & $15(30.6)$ & $27(55.1)$ & 49 (35.8) & \\
\hline $\begin{array}{l}\text { American Indian } \\
\text { Alaska Native }\end{array}$ & 1 (16.7) & 1 (16.7) & 4 (66.7) & $6(4.4)$ & \\
\hline $\begin{array}{l}\text { Black/African } \\
\text { American }\end{array}$ & $1(0.25)$ & $1(0.25)$ & $2(0.5)$ & 4 (2.9) & \\
\hline $\begin{array}{c}\text { Native Hawaiian/ } \\
\text { Pacific Islander }\end{array}$ & $1(50.0)$ & $1(50.0)$ & $0(0.0)$ & $2(1.5)$ & \\
\hline Other & $0(0.0)$ & $1(9.1)$ & $10(90.9)$ & $11(8.0)$ & \\
\hline Student Religion & & & & & $18.76(0.765)$ \\
\hline Christian & $3(5.8)$ & $10(19.2)$ & $39(75.0)$ & $52(38.0)$ & \\
\hline Non-Christian & $12(15.2)$ & 15 (19.0) & $52(65.8)$ & $79(57.7)$ & \\
\hline Parent Religion & & & & & $23.60(0.485)$ \\
\hline Christian & $7(10.6)$ & $12(18.2)$ & $47(71.2)$ & $66(48.2)$ & \\
\hline Non-Christian & $7(10.8)$ & $13(20.0)$ & $45(69.2)$ & $65(47.4)$ & \\
\hline
\end{tabular}

All tests were controlled for possible confounding variables, which included gender, age, race, religion of the student, and religion of the parent. Finally, descriptive statistics were also reported for the survey's open-ended questions (Table 4).

\section{Results}

A total of 275 students were surveyed, aged 13 to 18 , with a mean age of $16.13(\mathrm{SD}=1.175)$. Demographic data regarding the age, gender, race, religion of student, and religion of parent were collected (Table 1). Over half $(n=164$, $59.6 \%$ ) of participants reported not having heard of HPV before. More male $(n=99)$ students reported not having heard about HPV compared to female $(\mathrm{n}=65)$ students (Table $3, \mathrm{p}<0.01)$. The majority $(70.2 \%, n=193)$ of students reported not having discussed the vaccine with their physician. One hundred and ten (40.0\%) students planned to receive the HPV vaccine (62 males and 48 females), with no significant gender $(\mathrm{p}>0.2)$ or age $(\mathrm{p}>0.9)$ differences. 


\section{Table 3}

Logistic Regression of Outcome Variables on Demographic Characteristics

\begin{tabular}{|c|c|c|c|c|c|}
\hline & $\begin{array}{r}\text { Heard of } \\
\text { HPV } \\
\text { OR (p) }\end{array}$ & $\begin{array}{r}\text { Received the } \\
\text { Vaccine } \\
\text { OR (p) }\end{array}$ & $\begin{array}{r}\text { Plan to } \\
\text { receive the } \\
\text { vaccine } \\
\text { OR (p) }\end{array}$ & $\begin{array}{r}\text { Interest in } \\
\text { learning } \\
\text { more } \\
\text { OR (p) }\end{array}$ & $\begin{array}{r}\text { Physician } \\
\text { discussed } \\
\text { the vaccine } \\
\text { OR (p) }\end{array}$ \\
\hline Age & $1.63(0.00)$ & 1.121 (0.39) & $1.003(0.98)$ & $1.078(0.51)$ & $1.339(0.06)$ \\
\hline Gender & $1.34(0.28)$ & $3.108(0.00)$ & $1.209(0.50)$ & $0.775(0.34)$ & $6.064(0.00)$ \\
\hline $\begin{array}{l}\text { Ethnicity } \\
\text { Student's }\end{array}$ & $0.939(0.46)$ & $1.1018(0.85)$ & $1.158(0.09)$ & 1.109 (0.32) & $0.994(0.96)$ \\
\hline $\begin{array}{l}\text { religion } \\
\text { Parent's }\end{array}$ & $0.946(0.61)$ & $1.126(0.31)$ & $0.928(0.50)$ & $1.100(0.37)$ & $0.955(0.72)$ \\
\hline religion† & $1.062(0.54)$ & $0.891(0.27)$ & $0.988(0.90)$ & $0.969(0.75)$ & $0.865(0.22)$ \\
\hline
\end{tabular}

$\dagger$ Indicates that Christian is being compared to non-Christian religious faiths

Eighty six (31.3\%) students reported receiving the HPV vaccine, and of these, 9.4\% (n=26) reported receiving all 3 doses (Table 2). The majority of students $(85.7 \% \mathrm{n}=233)$ did not know if they had received the vaccine or how many doses they had received (Table 2). Chisquare tests found that females and students who labeled their race as "white", were more likely to complete the vaccine series (Table 2, $\mathrm{p}<0.001$ and $\mathrm{p}<0.03$, respectively). The binary logistic regression model found that older students were more likely to have heard of HPV (Table 3, $\mathrm{p}<0.001$, OR $=1.625$ ). Females were more likely to initiate the vaccine series (Table $3, \mathrm{p}<0.001$, $\mathrm{OR}=3.108$ ), and to have a physician discuss the vaccine with them (Table 3, $\mathrm{p}<0.001$, $\mathrm{OR}=6.064$ ). Additionally, while controlling for gender, age, race, student's religion, and parent's religion, it was found that students who had heard of HPV, or had a physician discuss the vaccine with them were more likely to receive the vaccine $(\mathrm{p}<0.001, \mathrm{OR}=13.222$ and $\mathrm{p}<0.001, \mathrm{OR}=8.065$, respectively).

A linear regression model found a significant relationship between physician discussing the vaccine and the following variables: heard of $\mathrm{HPV}$, interested in learning more about HPV, and vaccine dose received. Students who had a physician discuss the vaccine with them were more likely to have heard of HPV, were more interested in learning more about HPV, and had received a more complete vaccine dose $(\mathrm{p}<0.001)$. A lack of vaccine knowledge, among other factors, was the main reason students reported for not receiving the HPV vaccine (Table 4). Additionally, the main question students had regarding HPV and the HPV vaccine was “what is it?” (Table 4).

\section{Discussion}

The findings of this study emphasize the importance of promoting the role of physicians within HPV education campaign. Active participation by a physician may result in greater adolescent HPV knowledge, as well as increases in vaccine uptake and initiation rates. Our convenience sample included youth of various ethnic backgrounds, and moreover, the school in which our sample was drawn was given a high diversity rank among California high schools (Los Angeles Times, 2011). According to state data, the student body was $51.0 \%$ Asian, 34.9\% White, 6.9\% Latino, 2.1\% Black, and 5.2\% other (Los Angeles Times, 2011). These percentages are approximately representative of the school district in which the study sample was drawn, which consists of $43.3 \%$ Asian, 35.6\% white, 10.2\% Latino, $2.3 \%$ Black, and $8.5 \%$ other (California Department of Education, 2012). Our sample, which appeared to represent the population of interest had low awareness of health risks associated with HPV. 


\section{Table 4}

What Students Reported Wanting to Learn about HPV and Reasons for Lack of Interest

\begin{tabular}{|c|c|c|c|}
\hline \multicolumn{2}{|l|}{ Want to learn(\%*) } & \multicolumn{2}{|c|}{ Why not interested(\%*) } \\
\hline "What is it"? & $91(43.3)$ & $\begin{array}{l}\text { I don't know what } \\
\text { HPV is }\end{array}$ & $65(37.1)$ \\
\hline "I am interested in learning more & & I did not know & \\
\hline about the vaccine/prevention methods" & $35(16.7)$ & $\begin{array}{l}\text { about the HPV } \\
\text { vaccine }\end{array}$ & $38(21.7)$ \\
\hline "What are the symptoms" & $31(14.8)$ & $\begin{array}{l}\text { I do not need the } \\
\text { HPV vaccine }\end{array}$ & $32(18.3)$ \\
\hline "How is it spread" & $23(11.0)$ & $\begin{array}{l}\text { More than one } \\
\text { reason }\end{array}$ & $20(11.4)$ \\
\hline "Dangers of HPV” & $13(6.2)$ & Other & $15(8.6)$ \\
\hline "What are the chances it'll affect me" & $10(4.8)$ & It is too expensive & $2(1.1)$ \\
\hline “Treatment options” & $4(1.9)$ & $\begin{array}{l}\text { Cultural/religious } \\
\text { reasons }\end{array}$ & $2(1.1)$ \\
\hline "Is there a cure" & $3(1.4)$ & $\begin{array}{l}\text { My Insurance does } \\
\text { not cover it }\end{array}$ & $1(0.6)$ \\
\hline Total Respondents & $210(76.4 * *)$ & Total Respondents & $175\left(63.7^{* *}\right)$ \\
\hline
\end{tabular}

Many students in our study mentioned their general interest in protecting themselves. While $50.8 \%$ of students were interested in learning more about HPV, 70\% of students reported that a physician had not discussed the HPV vaccine with them. Additionally, $76 \%$ of students responded with a question when asked what they wanted to learn. With such a large percentage of students showing an interest in HPV education, having more physicians discuss the vaccine with children and parents could become a critical and effective aspect of HPV education campaigns (Safeer \& Keenan, 2005). This is further supported with the study's key finding that there is a strong positive correlation between a physician discussing the HPV vaccine and the following variables: HPV knowledge, interest in learning more, and vaccine uptake. Another key finding was that students that had prior HPV knowledge were significantly more likely to receive the vaccine. Such findings emphasize the importance of promoting the role of physicians within HPV education campaigns.

Few studies have examined HPV knowledge of both young men and women. This study found that there is a very significant gender gap in HPV discussion and vaccination rates, regardless of their risk of contracting HPV or their interest in learning more about HPV. More specifically, it was found that physicians were more likely to discuss the HPV vaccine with females and more females than males reported receiving the vaccine. As such HPV education campaigns should benefit from targeting both male and female adolescents in interventions tailored by gender. Future education campaigns should encourage physicians to discuss the vaccine with both male and female adolescent patients, as well as parents. With less than $10 \%$ of students reporting having received the full vaccine series, it has become increasingly important for children and parents to receive HPV information as soon as their child enters their early teens. Early vaccination ensures that children receive preventive care before being exposed to the virus, which will decrease the prevalence of HPV.

Implications for this study include both the potential to decrease the gender gap in HPV knowledge and promote the initiation of the 
HPV vaccine series among adolescents. Educating adolescents will also have the added benefit of educating parents, and research shows that parents not being educated are a hindrance to vaccination rates (Mergler et al., 2013). The sooner females are vaccinated, the lower the risk of developing chronic HPV infection and cervical cancer in the next 25 years (Vuyst, Clifford, Nascimento, Madeleine, \& Franceschi, 2009). By increasing HPV knowledge among the adolescent population, there will be a decreased exposure to HPV strains like HPV16/18, thereby helping to control the increasing rates of vulvar, vaginal, and anal carcinomas - particularly among women (Tsu, Murray, \& Franceschi, 2012).

\section{Limitations}

One important limitation in this study was a lack of access to a wider range of schools within the district. Very few schools were willing to have their students surveyed, preventing expansion to other schools. The students surveyed were attending high school in a high income neighborhood and had access to a sex education course in year three; therefore the significant rise in HPV knowledge between age groups could be attributed to this confounding variable. Future studies should examine the role of sexual education courses on HPV knowledge and vaccine uptake, and compare schools with and without such curriculum on outcomes such as HPV knowledge and vaccine uptake.

\section{Conclusion}

In sum, our findings suggest that education, gender, race, and having discussed HPV with one's physician play a crucial role in HPV vaccine uptake and initiation. Due to the increasing risk of HPV exposure among both young boys and girls, health professionals should be taking more extensive measures towards educating adolescents. HPV education campaigns among adolescent populations have not been working. Our findings suggest that both education and gender play a crucial role in HPV vaccine uptake and initiation. Physicians play a critical role in the rate of vaccine uptake among the adolescent population, and so should discuss HPV and the HPV vaccine to adolescents before the onset of sexual activity. Future education campaigns should target physicians and encourage them to discuss the vaccine with both their adolescent patients as well as their parents, both male and female.

\section{Acknowledgements}

The authors would like to thank the students, principal, and teachers at high school where the sample was drawn who chose to participate in the study. Additionally, we would like to thank the IRB for guiding the ethics of conducting the study. Thanks to Ms. Sandra Perez, CAO of GHREAT, for editorial support. 


\section{References}

Ajzen, I. (1991). The theory of planned behavior. Organizational Behavior and Human Decision Processes, 50, 179-211. DOI: 10.1016/0749-5978(91)90020-T.

Beatty, B.G., O'Connell, M., Ashikaga, T., \& Cooper, K. (2003). Human papillomavirus (HPV) education in middle and high schools of Vermont. Journal of School Health, 73(7), 253-257. DOI: 10.1111/j.1746-1561.2003.tb06573.x.

Brown, B., Carcamo, C., Blas, M.M., Valderrama, M., \& Halsey, N. (2010). Peruvian FSWs: understanding HPV and barriers to vaccination. Vaccine, 28(49), 7743-7747.

California Department of Education. (2012). District Level Data. Retrieved from http://www.cde.ca.gov/ds/.

Center for Disease Control and Prevention. (2012) Human Papillomavirus (HPV). Retrieved from http://www.cdc.gov/std/stats12/adol.htm.

Centers for Disease Control and Prevention (CDC). (2012). National and state vaccination coverage among adolescents aged 13-17 years--United States, 2011. MMWR. Morbidity and Mortality Weekly Report, 61(34), 671.

Center for Disease Control and Prevention. (2014). Youth Risk Behavior surveillance. Retrieved from http://www.cdc.gov/mmwr/pdf/ss/ss6304.pdf.

Colgrove, J., Abiola, S., \& Mello, M.M. (2010). HPV vaccination mandates-lawmaking amid political and scientific controversy. New England Journal of Medicine, 363(8), 785-791.

Damin, D.C., Ziegelmann, P.K., \& Damin, A.P. (2013). Human papillomavirus infection and colorectal cancer risk: A meta-analysis. Colorectal Disease. DOI: 10.1111/codi.12257.

De Vuyst, H., Clifford, G.M., Nascimento, M.C., Madeleine, M.M., \& Franceschi, S. (2009). Prevalence and type distribution of human papillomavirus in carcinoma and intraepithelial neoplasia of the vulva, vagina and anus: A meta-analysis. International Journal of Cancer, 124(7), 1626-1636.

Friedman, A.L., \& Sheppard, H. (2007). Exploring the Knowledge, Attitudes, Beliefs, and Communication Preferences of the General Public Regarding HPV Findings From CDC Focus Group Research and Implications for Practice. Health Education \& Behavior, 34(3), 471-485.

Gravitt, P.E. (2011). The known unknowns of HPV natural history. The Journal of Clinical Investigation, 121(12), 4593-4599.

Hariri, S., Unger, E.R., Sternberg, M., Dunne, E.F., Swan, D., Patel, S., \& Markowitz, L.E. (2011). Prevalence of genital human papillomavirus among females in the United States, the National Health and Nutrition Examination Survey, 2003-2006. Journal of Infectious Diseases, 204(4), 566-573.DOI: 10.1093/infdis/jir341.

Hirth, JM, A. Tan, GS Wilkinson, and AB Berenson, (2012). Completion of the Human Papillomavirus Vaccine Series among Insured Females between 2006 and 2009. Cancer. 188 (22), pp.56235629. DOI: $10.1002 /$ cncr.27598.

Jin, X.W., Lipold, L., Sikon, A., \& Rome, E. (2013). Human papillomavirus vaccine: Safe, effective, underused. Cleveland Clinic Journal of Medicine, 80(1), 49-60.

Lambert, E.C. (2001). College students' knowledge of human papillomavirus and effectiveness of a brief educational intervention. The Journal of the American Board of Family Practice, 14(3), 178-183.

Los Angeles Times. (2011). California Schools Guide. Retrieved from http://schools.latimes.com/.

Markowitz, L.E., Hariri, S., Lin, C., Dunne, E.F., Steinau, M., McQuillan, G., \& Unger, E.R. (2013). Reduction in human papillomavirus (HPV) prevalence among young women following HPV vaccine introduction in the United States, National Health and Nutrition Examination Surveys, 2003-2010. Journal of Infectious Diseases, jit192.

Mergler, M.J., Omer, S.B., Pan, W.K., Navar-Boggan, A.M., Orenstein, W., Marcuse, E.K., \& Salmon, D.A. (2013). Association of vaccine-related attitudes and beliefs between parents and health care providers. Vaccine, 31(41), 4591-4595.

Rosenstock, I. M. (1974). The Health Belief Model and Preventive Health Behavior. Health Education and Behavior, 2(4), 354-386. 
Safeer, R.S. \& Keenan, J. (2005). Health literacy: The gap between physicians and patients. American Family Physician, 72(3), 463-468.

Sparks, L., \& Villagran, M. (2010). Patient and provider interaction: A global health communication perspective. Cambridge, UK, Polity Press.

Tsu, V., Murray, M., \& Franceschi, S. (2012). Human papillomavirus vaccination in low-resource countries: Lack of evidence to support vaccinating sexually active women. British Journal of Cancer, 107, 1445-1450.

U.S. Department of Health and Human Services (2013). Cervical Cancer. Retrieved from http://www.report.nih.gov/nihfactsheets/ViewFactSheet.aspx?csid=76

U.S. Department of Health and Human Services. (2014). Office of Adolescent Health. http://www.hhs.gov/ash/oah/adolescent-health-topics/reproductive-health/stds.html\#ftn1

U.S. National Institutes of Health.(2012). Human Papilloma Virus (HPV) Vaccine Efficacy Trial Against Cervical Pre-cancer in Young Adults With GlaxoSmithKline (GSK) Biologicals HPV-16/18. Retrieved from http://clinicaltrials.gov/ct2/show/results/NCT00122681.

\author{
Author Information \\ *Parastou Sadat Khalessi Hosseinia , B.S.,B.A \\ University of California, Irvine \\ Irvine, CA 92697 \\ pkhaless@uci.edu \\ Karen Munoza ,B.S., B.A \\ University of California, Irvine \\ Irvine, CA 92697 \\ kmunoz@uci.edu \\ Cynthia M. Lakona, Ph.D \\ University of California, Irvine \\ Irvine, CA 92697 \\ clakon@hs.uci.edu \\ Brandon Browna, M.P.H, Ph.D \\ University of California, Irvine \\ Irvine, CA 92697 \\ brandon.brown@uci.edu \\ * corresponding author
}

